\title{
A general strategy to optimize immunogenicity of HLA-B*0702 restricted cryptic peptides from tumor associated antigens: Design of universal neo-antigen like tumor vaccines for HLA-B*0702 positive patients
}

\author{
Catherine Gallou ${ }^{1}$, Aude Rougeot ${ }^{1}$,Stéphanie Graff-Dubois ${ }^{2}$, Kostas Kosmatopoulos ${ }^{1}$, \\ Jeanne Menez-Jamet ${ }^{1}$ \\ ${ }^{1}$ Vaxon Biotech, 75015, Paris, France \\ ${ }^{2}$ University Pierre-and-Marie-Curie (aka University Paris 06), INSERM U1135, CNRS ERL8255, 75013, Paris, France
}

Correspondence to: Jeanne Menez-Jamet, email: jmenez@vaxon-biotech.com

Keywords: HLA-B7, vaccination, immunotherapy, optimized, cryptic

Received: May 27, 2016 Accepted: July 13, $2016 \quad$ Published: August 05, 2016

\section{ABSTRACT}

Tumor Associated Antigens (TAAs) are the privileged targets of almost all the cancer vaccines tested to date. Unfortunately all these vaccines failed to show a clinical efficacy. The main reason for this failure is the immune tolerance to TAAs that are self-proteins expressed by normal and cancer cells. Self-tolerance to TAAs is directed against their dominant rather than against their cryptic epitopes. The best way to overcome self-tolerance to TAAs would therefore be to target their cryptic epitopes. However, because of their low HLA-I affinity, cryptic peptides are nonimmunogenic and cannot be used to stimulate an antitumor immune response unless their immunogenicity has been previously enhanced. In this paper we describe a general approach to enhance immunogenicity of almost all the HLA-B*0702 restricted cryptic peptides derived from TAAs. It consists in substituting residues at position 1 or 9 of low HLA-B*0702 affinity cryptic peptides by an Alanine or a Leucine respectively. These substitutions increase affinity of peptides for HLA-B*0702. These optimized cryptic peptides are strongly immunogenic and very importantly CTL they stimulate recognize their native counterparts.

TAAs derived optimized cryptic peptides can be considered as universal antitumor vaccine since they escape self-tolerance, are immunogenic and are not patient specific.

\section{INTRODUCTION}

Immunotherapy based on Tumor Associated Antigens (TAAs) vaccination was a therapeutic approach which is the subject of a great interest during the last decade in the context of cancer treatment. The unique approach was to immunize with full length TAAs or derived antigenic peptides that stimulate Cytotoxic T Lymphocytes (CTLs), which play a major role in the elimination of tumor cells. Unfortunately, all preclinical and clinical studies were found to elicit only weak immunological responses with poor benefits in clinical studies [1-9]. Recently the use of MAGE full length antigen failed to reach the phase III objectives in the MAGRIT trial, the most important clinical study launched in cancer vaccination $[9,10]$.

Several factors may explain these disappointing results but the most likely is that dominant peptides targeted by all these vaccines are submitted to the central and peripheral self-tolerance, since all TAAs are non-mutated self-proteins expressed by normal tissues, including thymus. To overcome this issue, two ways were explored, i) recruiting the low affinity CTLs that could have escaped to central tolerance; major efforts were focused on the development of strong adjuvants that could strengthen immune response (for review see [11]); however the failure of the MAGE-A/ASCI vaccine that used a very powerful adjuvant showed that this way was wrong $[9,10]$, ii) identifying tumour specific immunogenic antigens. These antigens are abnormal proteins harbouring somatic mutations and are very often patient specific. All these mutations create T-cell reactive epitopes, called neoantigens, which are recognized by the immune system as non-self and escape the self-tolerance process. Recently, the area of serial tumour genomic sequencing has allowed the identification of such neo-antigens and opened the way 
to personalized peptide based therapy [12]. However, neoantigen must be identified for each patient individually that makes their use extremely difficult and expensive. Moreover, the use of neo-antigens as cancer vaccines may be limited by the genetic heterogeneity of tumors, indeed neo-antigens may be expressed by some but not all lesions of the same tumor.

We have previously described a new class of cancer vaccines. Like neo-antigens, these peptidic vaccines escape self -tolerance and are strongly immunogenic while, unlike neo-antigens, they can be used for the vaccination of all cancer patients.

These neo-antigen like universal cancer vaccines are called "optimized cryptic peptides". Optimized cryptic peptides escape self-tolerance because they target TAAs derived cryptic peptides that are not involved in selftolerance process and they are strongly immunogenic because their immunogenicity is optimized. The strategy to optimize immunogenicity of cryptic peptides, that because of their low MHC I affinity are non-immunogenic, consists in increasing their affinity for the MHC I molecules via amino acids substitutions [13]. These substitutions should however preserve the antigenicity of such optimized peptides. CTL generated by optimized peptides should indeed cross-react with the corresponding native peptides, which are presented at the tumor cell surface.

We have previously identified rules of selection and optimisation of HLA-A*0201 restricted cryptic peptides $[8,13]$, expressed by $45 \%$ of human population. Vx-001, the first optimized cryptic peptide based vaccine was already tested in a phase I/II study and was shown to be safe and strongly immunogenic in a majority of vaccinated patients [14-16]. Vx-001 is currently in Phase IIb double blind clinical study in stage IV NSCLC patients [17].

In this study, we investigated how to optimize tumor cryptic peptides presented by the HLA-B*0702 molecule, a $\mathrm{CMH}$ allele expressed by $25 \%$ of humans. We describe a general strategy to optimize HLA-B*0702 restricted cryptic peptides having a proline and an arginine at positions 2 and 3 respectively. It consists in substituting residues at positions 1 or C-terminal by an alanine and a leucine respectively.

This results open the way to the development of therapeutic vaccine designated to HLA-B*0702 cancer patients.

\section{RESULTS}

\section{Selection of low HLA-B*0702 affinity non immunogenic peptides}

It is well established that the immunogenicity of a peptide depends on its affinity for HLA molecules. High affinity peptides are immunogenic while low affinity peptides are not. HLA affinity depends on the presence/ absence of primary anchor motifs and often on the presence of secondary anchor motifs that are both HLA allele specific.
For instance peptides bound to HLA-B*0702 have a proline $(\mathrm{P})$ and a leucine $(\mathrm{L})$ or a methionine $(\mathrm{M})$ at positions 2 and C-terminal respectively as primary anchor motifs. Regarding the secondary anchor positions, an alanine (A) at position 1 and an arginine $(\mathrm{R})$ at position 3 are described to be favourable for binding to HLA-B*0702 [18].

We have previously described that the best method for identifying cryptic epitopes, that have a low HLA affinity consists in selecting from an antigen, peptides of 9/10 amino acids, having favourable primary anchor residues and non-favourable amino acids in at least one secondary anchor position $[8,13]$. In the case of HLA-B*0702, optimally selected peptides must have a proline in position 2 , and a leucine or a methionine in C-terminal position, and non-favourable amino acids at the secondary anchor position (1 and/or 3).

According to this rule, eight peptides with the HLA-B*0702 specific anchor motifs (P at position 2 and preferentially L/M at C-terminal position), derived from the universal antigens, Hsp70, TERT and the MAGE-A family (MAGE-A1, A2, A3, A4, A6, A10 and A12) were designed in silico and tested for binding to the HLA-B*0702 molecule. One peptide (TERT ${ }_{4}$ ) harbouring the complete consensus motif i.e. A1P2R3L9 was also selected as a control.

Selected cryptic peptides were very weak or even non HLA-B*0702 binders (Table 1), with relative affinity not evaluable (superior to 10). This confirms the importance of the secondary anchor residues since the presence of primary anchor motifs is not sufficient by itself to ensure a high binding affinity to HLA-B*0702. TERT $_{4}$ that harbours the consensus sequence was shown to strongly bind to HLA-B*0702 (Table 1).

Given their low affinity, peptides Hsp $70_{115}, H_{s p} 70_{137}$, $\mathrm{Hsp}_{307}$, TERT $_{444}$, MAGE-A1 $1_{121}$, MAGE-A2 ${ }_{121}$ and MAGE-A $4_{121}$ are considered cryptic peptides.

TERT $_{4}$ in contrast has a strong affinity for HLA-B*0702, and is considered dominant peptide.

The low affinity $\mathrm{Hsp}_{137}, \mathrm{Hsp}_{115}, \mathrm{Hsp}_{397}, \mathrm{TERT}_{444}$ and the high affinity TERT $_{4}$ peptides have been tested for their capacity to induce a specific CTL immune response in humanized HLA-B*0702 transgenic mice. As expected only the high affinity TERT $_{4}$ was immunogenic confirming that immunogenicity of peptides is strongly related to their affinity for HLA (Figure 1).

\section{Optimization of HLA-B*0702 affinity and in vivo immunogenicity of peptides harbouring substitutions at secondary anchor positions}

Since all these cryptic peptides had favourable primary anchor motifs, enhancement of their affinity that is a prerequisite for them to be immunogenic, would require the modification of unfavourable secondary anchor motifs and their substitution with favourable amino acids. These substitutions should however preserve the conformation of 
Table 1: HLA-B*0702 affinity of peptides

\begin{tabular}{l|c|c|c|}
\hline antigen & peptide & séquence & RA \\
\hline TERT & TERT $_{4}$ & APRCRAVRSL & $0.74 \pm 0.12$ \\
\hline Hsp70 & Hsp70 $_{115}$ & YPEEISSMVL & $\geq 10$ \\
\hline & Hsp70 $_{137}$ & YPVTNAVITV & $\geq 10$ \\
\hline & Hsp70 $_{397}$ & APLSLGLET & $\geq 10$ \\
\hline TERT & TERT $_{444}$ & DPRRLVQLL & $\geq 10$ \\
\hline MAGE-A & MAGE-A1 $_{121}$ & EPVTKAEML & $\geq 10$ \\
\hline & MAGE-A2 $_{121}$ & EPFTKAEML & $\geq 10$ \\
\hline
\end{tabular}

RA: Relative Affinity; $\geq 10$ means that RA can be 10 or not measurable because the affinity is less than $20 \%$ of the standard peptide affinity. Each experiment was reproduced at least three times giving similar results, mean values and standard deviation are reported in the table.
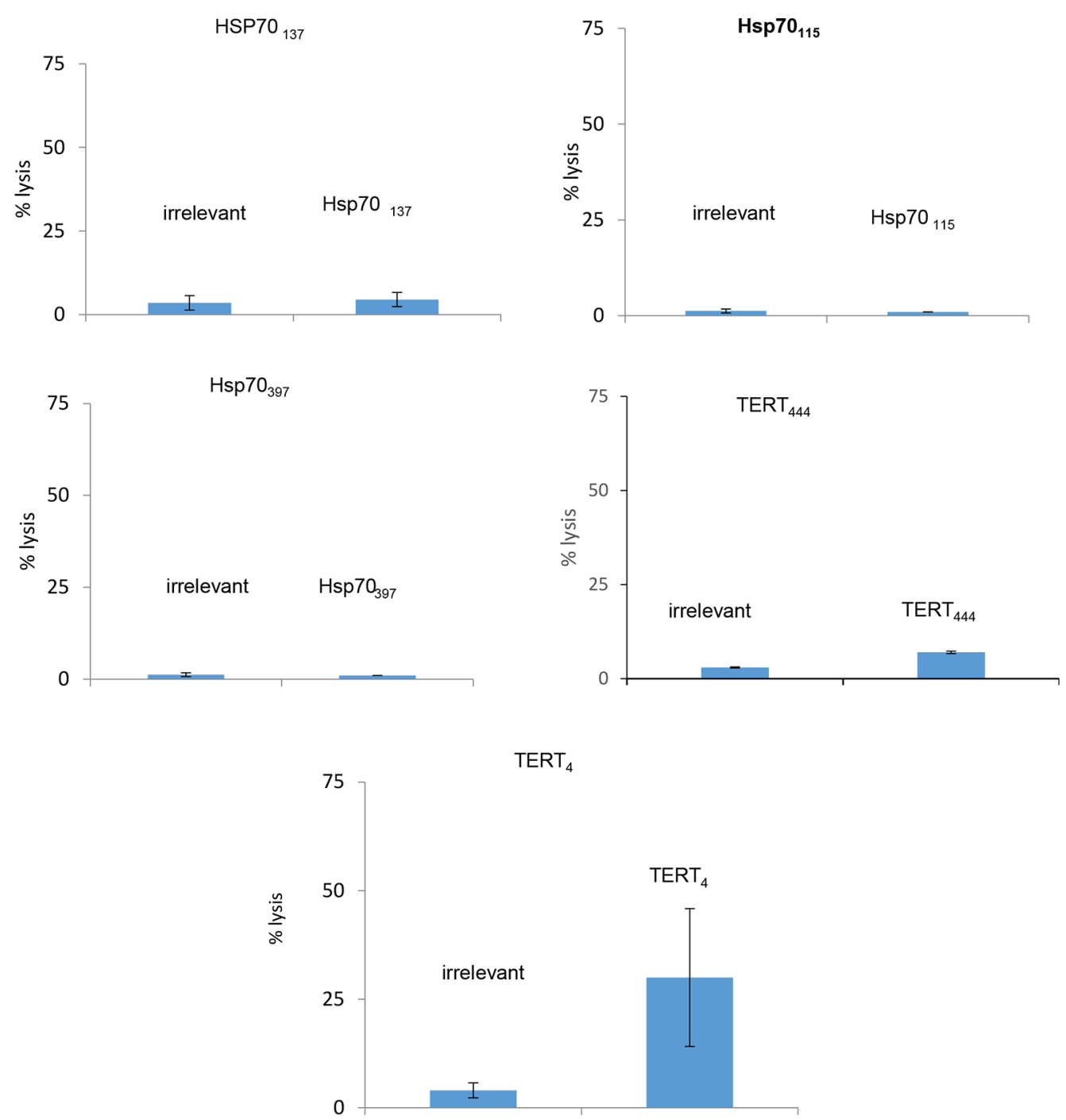

Figure 1: Cytotoxicity of murine CTLs from HLA-B*0702 transgenic mice vaccinated with native peptides. Six HLA-B*0702 transgenic mice were vaccinated with each of the selected native peptides. Specific CTLs induction was evaluated by the capacity of lymphocytes from spleen cells to lyse target cells loaded with an irrelevant peptide or the peptide used for vaccination (ratio 30/1). 
the peptide segment that interacts with the TCR (usually position 3 to position 8 for a 9 -mer).

As previously described, an alanine at position 1 and an arginine at position 3 are favourable [18]. Our interest was, therefore, focused on secondary anchor positions 1 and 3.

For cryptic peptides $\mathrm{Hsp}_{115}, \mathrm{Hsp}_{397}, \mathrm{TERT}_{444}$ and MAGE-A $1_{121}$ non-favourable secondary anchor motifs were respectively replaced by an alanine at position 1 and arginine at position 3 (Table 2). For Hsp70 ${ }_{397}$ the unfavourable leucine at position 3 was replaced by an arginine and an additional modification (replacement of a threonine by a leucine) was brought at the C-terminal position to increase the predicted immunogenicity.

Results presented in Table 2 show that the presence of a favourable motif at secondary positions 3 is absolutely necessary for a peptide to have a high HLA-B*0702 affinity. This is the case of peptides Hsp70 ${ }_{115} \mathrm{~A} 1 \mathrm{R} 3$, $\mathrm{Hsp}_{70}{ }_{397} \mathrm{R} 3 \mathrm{~L} 9, \mathrm{TERT}_{444} \mathrm{~A} 1$, MAGE-A1 ${ }_{121} \mathrm{~A} 1 \mathrm{R} 3$. It is noteworthy that the high affinity $\mathrm{TERT}_{4}$ has favourable residues at both positions 1 and 3. Inversely peptides with favourable residue at only position 1 fail to bind to HLA-B*0702 with high affinity. This is the case of Hsp70 ${ }_{115} \mathrm{~A} 1$ and MAGE-A1 $1_{121} \mathrm{~A} 1$.

These results suggest that binding motifs for HLA-B*0702 are more stringent than for HLA-A*0201 for which position 3 is not determinant and suggest that for HLA-B*0702 position 3 could be considered as a primary anchor position.

Optimized cryptic peptides Hsp70 ${ }_{115} \mathrm{~A} 1 \mathrm{R} 3$, $\mathrm{Hsp}_{70}{ }_{397} \mathrm{R} 3 \mathrm{~L} 9$ and $\mathrm{TERT}_{444} \mathrm{~A} 1$ were then tested in HLA-B*0702 transgenic mice for their capacity to stimulate CTL able to recognize their native counterpart.

Figure 2 shows that all tested high affinity optimized peptides were strongly immunogenic confirming once again the correlation between high binding affinity and immunogenicity.

However, for all these peptides but $\mathrm{TERT}_{444} \mathrm{~A} 1$, generated CTL recognized target cells loaded with the optimized peptide but not the corresponding native peptide. This strongly suggests that substitution of residues at position 3 changes the conformation of the peptide segment that interacts with the TCR and guarantees the TCR cross-recognition of the native counterpart.

Since the native peptide cross-recognition by the optimized peptide induced CTL is mandatory for a vaccine candidate, because the native peptide is the only one that is expressed at the tumour cell surface, new rules of native peptide selection and optimization were investigated.

\section{Selection of cryptic peptides with favourable amino acids at positions 2 and 3}

Since a) the presence of favourable residues at both position 1 and 3 is necessary for a peptide to strongly bind to HLA-B*0702 and b) a modification of the residue at position 3 alters the interaction of the specific TCR and the HLA-B*0702/peptide complex thus preventing the recognition of the native counterpart, we proceeded to the selection of peptides that have favourable residues at position 2 and 3 and unfavourable residues at position 1 or 9. Theoretically, these peptides should have a low affinity for HLA-B*0702 and optimization of their affinity should require modification of the residue at position 1 and/or 9 that should not have an impact on the TCR/ HLA-B*0702/peptide interaction. Except a proline, no other aminoacids are described to be unfavourable at position 1 (http://www-bimas.cit.nih.gov/cgi-bin/molbio/ hla_coefficient_viewing_page). In this context, the probability to select high affinity immunogenic native peptide increases dramatically.

Ten peptides were selected according to these rules, HER 2/neu ${ }_{246}, \mathrm{HER} 2 / \mathrm{neu}_{760}, \mathrm{HER} 2 / \mathrm{neu}_{1069}, \mathrm{HER} 2 / \mathrm{neu}_{1151}$, $\mathrm{HSP}_{406}, \mathrm{CEA}_{188,}, \mathrm{P}_{43}{ }_{63},{\mathrm{MAGE}-\mathrm{A} 1_{267}, \text { MAGE-A2 }}_{274}$ and MAGE-A $3_{274}$ and directly tested in HLA-B*0702 transgenic mice to rapidly select non immunogenic peptides (Table 3). It is noteworthy that each peptide sequence derived from MAGE-A is present in two genes of the MAGE-A family: MAGE-A $1_{267}$ is shared by MAGE-A1 and MAGE-A4, MAGE-A2 274 is shared by MAGE-A2 and MAGE-A6 and MAGE-A ${ }_{274}$ is shared by MAGE-A3 and MAGE-A12. Moreover, all these sequences are homolog and differ only at position 6 (Table 3).

HER 2/neu ${ }_{760}, \mathrm{HER} 2 / \mathrm{neu}_{1151}, \quad \mathrm{HSP}_{466}, \mathrm{P} 53_{63}$ and HER2/neu ${ }_{1069}$ native peptides were shown to be immunogenic in HLA-B*0702 transgenic mice and were withdrawn from the selection process. In contrast, HER2/ neu $_{246},{\mathrm{MAGE}-\mathrm{A} 1_{26}, \mathrm{MAGE}-\mathrm{A} 2_{274} \text { and CEA }}_{188}$ were non immunogenic and were selected to be further optimized (Table 3 and Figure 3).

A very weak immunogenicity (see Figure 3 ) was observed with MAGE-A3 ${ }_{274}$ which, in spite of that, was selected for further optimisation.

\section{Optimization of HLA-B $* 0702$ affinity and in vivo immunogenicity of non-immunogenic cryptic peptides with favourable amino acids at positions 2 and 3}

Optimized peptides Her2/neu ${ }_{246} \mathrm{~A} 1$ modified at position 1 by an alanine and $\mathrm{CEA}_{188}^{246} \mathrm{~L}$, modified at last position by a leucine were tested in HLA-B*0702 transgenic mice.

MAGE- ${ }_{274} \mathrm{~L} 9$ was derived from MAGE-A $3_{274}$, since MAGE-A3 ${ }_{274}$ is shared by MAGE-A3, the most expressed in tumour cells ( $46 \%$ in lung, $57 \%$ in gastric cancer, $68 \%$ in hepatocarcinoma, $76 \%$ in RCC) and MAGE-A12 expressed in 74\% of melanoma. MAGE$\mathrm{A}_{274} \mathrm{~L} 9$ optimized peptide was tested in HLA-B*0702 transgenic mice for immunogenicity and cross recognition 
Table 2: HLA-B*0702 affinity of peptides

\begin{tabular}{|c|c|c|}
\hline Peptide & sequence & RA \\
\hline $\mathrm{Hsp} 70_{115}$ & YPEEISSMVL & $\geq 10$ \\
\hline $\mathrm{Hsp70}{ }_{115} \mathrm{~A} 1$ & Apeeissmvl & $\geq 10$ \\
\hline $\mathrm{Hsp} 70_{115}$ A1R3 & ApReissmvl & $1.6 \pm 0.97$ \\
\hline $\mathrm{Hsp}_{30}$ & APLSLGLET & $\geq 10$ \\
\hline $\mathrm{Hsp}_{397} \mathrm{R} 3 \mathrm{~L} 9$ & APRSLGLEL & $1 \pm 0.6$ \\
\hline TERT $_{444}$ & DPRRLVQLL & $\geq 10$ \\
\hline $\mathrm{TERT}_{444} \mathrm{~A} 1$ & APRRLVQLL & $1.4 \pm 0.83$ \\
\hline MAGE-A1 $1_{121}$ & EPVTKAEML & $\geq 10$ \\
\hline MAGE-A1 ${ }_{121} \mathrm{~A} 1$ & APVTKAEML & $\geq 10$ \\
\hline MAGE-A1 ${ }_{121}$ A1R3 & APRTKAEML & $2.36 \pm 0.28$ \\
\hline
\end{tabular}

RA: Relative affinity of cryptic and optimized peptides; $\geq 10$ means that RA can be 10 to not measurable because it is not possible to determine the $20 \%$ of standard value. Each experiments was reproduced at least three times giving comparable results, mean values and standard deviation are reported in the Table.

of the corresponding native MAGE-A $3_{274}$ peptide and also against the two homolog native sequences MAGE-A $1_{267}$ and MAGE-A $2_{274}$.

Figure 3 shows that HER2/neu ${ }_{246} \mathrm{~A} 1, \mathrm{CEA}_{188} \mathrm{~L} 9$ and MAGE- $\mathrm{A}_{274} \mathrm{~L} 9$ optimized peptides are immunogenic in HLA-B*0702 transgenic mice. More importantly, induced CTLs are able to recognize target cells loaded with their corresponding native peptide. MAGE- $\mathrm{A}_{274} \mathrm{~L} 9$ induced CTLs were shown able to recognize target cells loaded with MAGE-A $3_{274}$ but also MAGE-A $1_{267}$ and MAGE-A2 ${ }_{274}$ homolog sequences (Table 4).
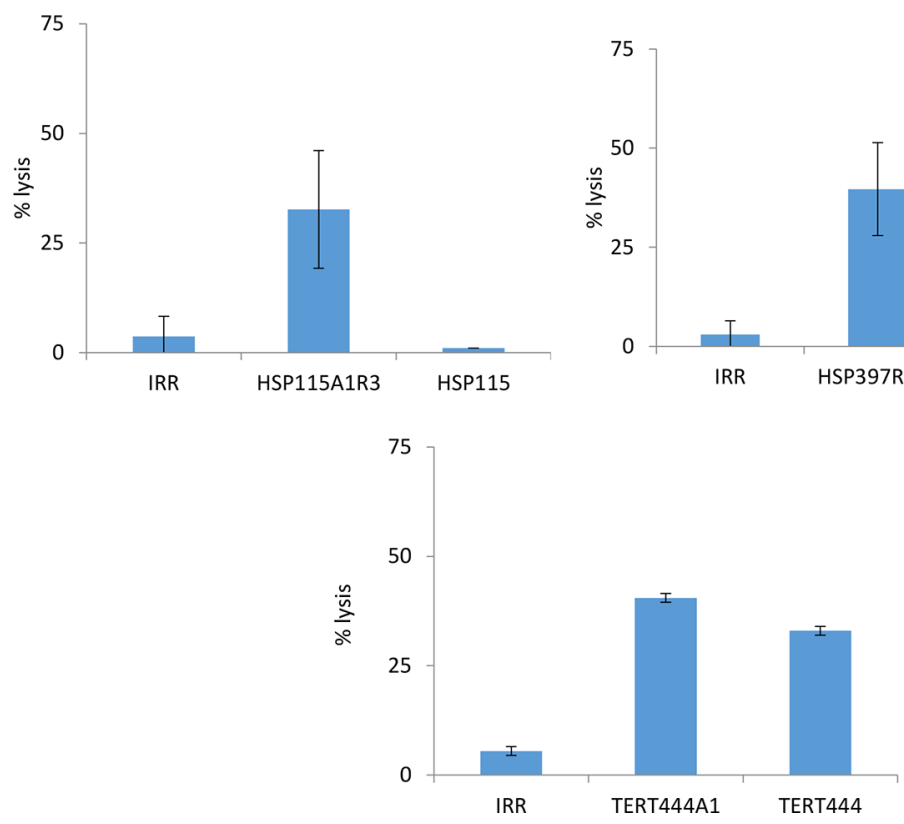

Figure 2: Cytotoxicity of murine CTLs from HLA-B*0702 transgenic mice vaccinated with optimized peptides. Three to six HLA-B*0702 transgenic mice were vaccinated with optimized peptides, and specific CTLs were tested against target cells loaded with an irrelevant peptide, the optimized peptide used for vaccination or the corresponding native peptide (ratio 30/1).

\section{Optimized cryptic peptides are immunogenic in vitro in human}

Four couple of native/optimized peptides previously validated in HLA-B*0702 transgenic mice: TERT $_{444^{-}}$ TERT $_{444} \mathrm{~A} 1, \mathrm{HER} 2 / \mathrm{neu}_{246}-\mathrm{HER} 2 / \mathrm{neu}_{246} \mathrm{~A} 1, \mathrm{MAGE}-\mathrm{A} 3{ }_{274} /$ MAGE-A ${ }_{267} /$ MAGE-A2 ${ }_{274}-$ MAGE-A $_{274}$ L9 and CEA ${ }_{188}{ }^{-}$ $\mathrm{CEA}_{188} \mathrm{~L} 9$ were tested in vitro for their capacity to induce specific CTLs from healthy PBMC donors.

$\mathrm{CD} 8+\mathrm{T}$ cells from healthy donors were in vitro stimulated with autologous dendritic cells loaded with

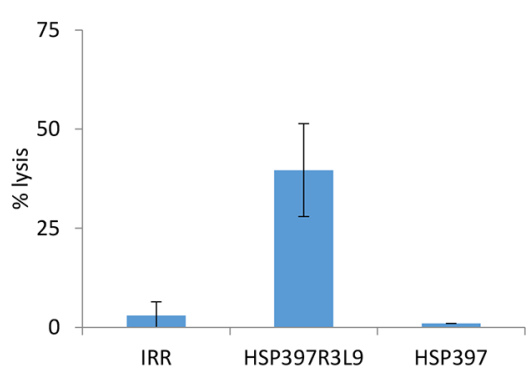


Table 3: Immunogenicity of native HLA-B*0702 restricted peptides, number of responding mice/number of vaccinated mice, peptides in grey were withdrawn from the selection process, *MAGE-A3 ${ }_{274}$ was selected for further optimization because the immune response it generated was very weak (see Figure 3)

\begin{tabular}{|c|c|c|c|}
\hline Antigen & Peptide & Sequence & Immunogenicity \\
\hline \multirow[t]{4}{*}{ Her2/neu } & Her2/neu ${ }_{760}$ & SPKANKEIL & $4 / 9$ \\
\hline & Her2/neu ${ }_{246}$ & GPKHSDCLA & $0 / 9$ \\
\hline & Her2/neu ${ }_{1069}$ & APRSPLAPS & $5 / 7$ \\
\hline & Her $2 /$ neu $_{1151}$ & SPREGPLPA & $1 / 3$ \\
\hline MAGE-A1 ; MAGE-A4 & MAGE-A1 ${ }_{267}$ & GPRALAETS & $0 / 3$ \\
\hline MAGE-A2; MAGE-A6 & MAGE-A2 274 & GPRALIETS & $0 / 3$ \\
\hline MAGE-A3, MAGE-A12 & MAGE-A $3_{274}$ & GPRALVETS & $2 / 3^{*}$ \\
\hline CEA & $\mathrm{CEA}_{188}$ & SPRLQLSND & $0 / 3$ \\
\hline HSP70 & $\mathrm{HSP}_{466}$ & APRGVPQIEV & $3 / 3$ \\
\hline $\mathrm{P} 53$ & $\mathrm{P} 53_{63}$ & APRMPEAAP & $3 / 3$ \\
\hline
\end{tabular}

each optimized cryptic peptide. After four stimulations, proliferating cells were tested for the presence of IFN $\gamma$ producing CTLs upon stimulation with T2-B7 cells loaded with optimized or native peptides either by intracellular IFN $\gamma$ staining or by IFN $\gamma$ ELISPOT assay.

Table 5 summarizes experiments with $\mathrm{TERT}_{444} \mathrm{~A} 1$, $\mathrm{HER} 2 / \mathrm{neu}_{246} \mathrm{~A} 1, \quad \mathrm{MAGE}-\mathrm{A}_{274} \mathrm{~L} 9$ and $\mathrm{CEA}_{188} \mathrm{~L} 9$. Immunogenicity of TERT ${ }_{444} \mathrm{~A} 1, \mathrm{HER} 2 / \mathrm{neu}_{246} \mathrm{~A} 1$, MAGE$\mathrm{A}_{274} \mathrm{~L} 9$ and $\mathrm{CEA}_{188} \mathrm{~L} 9$ was confirmed. More importantly, the specific CTLs induced by vaccinating with the optimized peptides were able to recognize target cells loaded with the optimized or with the corresponding native peptide confirming that optimized peptide specific CTLs are able to recognize the corresponding native peptide.

Regarding $\mathrm{MAGE}_{273} \mathrm{~L} 9$, the cross recognition of MAGE-A $3_{274}$ and MAGE-A2 $2_{274}$ was confirmed but not for MAGE-A1 $_{267}$ (Figure 4).

Figure 4 presents two representative experiments. Figure $4 \mathrm{~A}$ shows that IFN $\gamma$ producing CTLs were detected by IFN $\gamma$ intracellular staining in pools 2 and 4 after stimulation with either $\mathrm{TERT}_{444} \mathrm{~A}_{1}$ or $\mathrm{TERT}_{444}$ loaded T2B7 cells confirming the cross recognition of

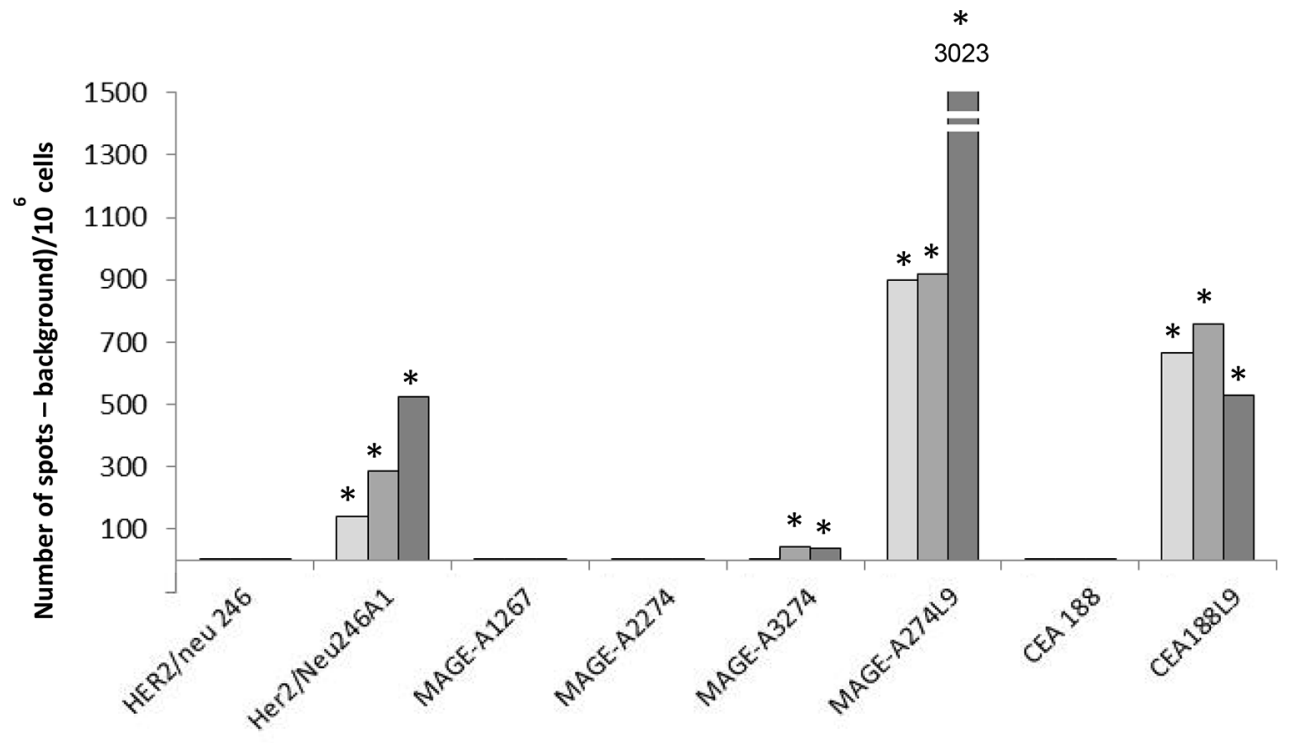

Figure 3: Immunogenicity of selected native and optimized peptides in HLA-B*0702 transgenic mice. Three HLA-B*0702 transgenic mice (clear, medium and dark gray respectively represents results of one mouse) were vaccinated twice at two weeks interval with the native or the optimized peptide. For each mouse, the number of specific CTLs was determined by ELISpot assay and expressed per $10^{6}$ cells. * means that difference are statistically significant from negative control $(p \leq 0.05)$. 
the native peptide by CTLs stimulated with the optimized one. Figure 4B shows a representative experiment with MAGE- $A_{274}$ L9. Significant specific immune responses were observed against MAGE-A $2_{274}$ and MAGE-A $3_{274}$ in pool 1 and 3 confirming the native peptides recognition. Cumulative experiments are presented in Table 5. As mentioned before MAGE-A1 $1_{267}$ was not recognized significantly in these experiments even if specific CTLs were detected (Figure 4B).

\section{DISCUSSION}

Despite a very promising concept, cancer vaccination gave disappointing clinical results in cancer patients. All cancer vaccines tested to date targeted TAAs that are self-proteins expressed by both tumor and normal cells. The main reason that explains the failure of cancer vaccines is immune tolerance to the self-antigens they targeted (self-tolerance). The necessity to circumvent

A

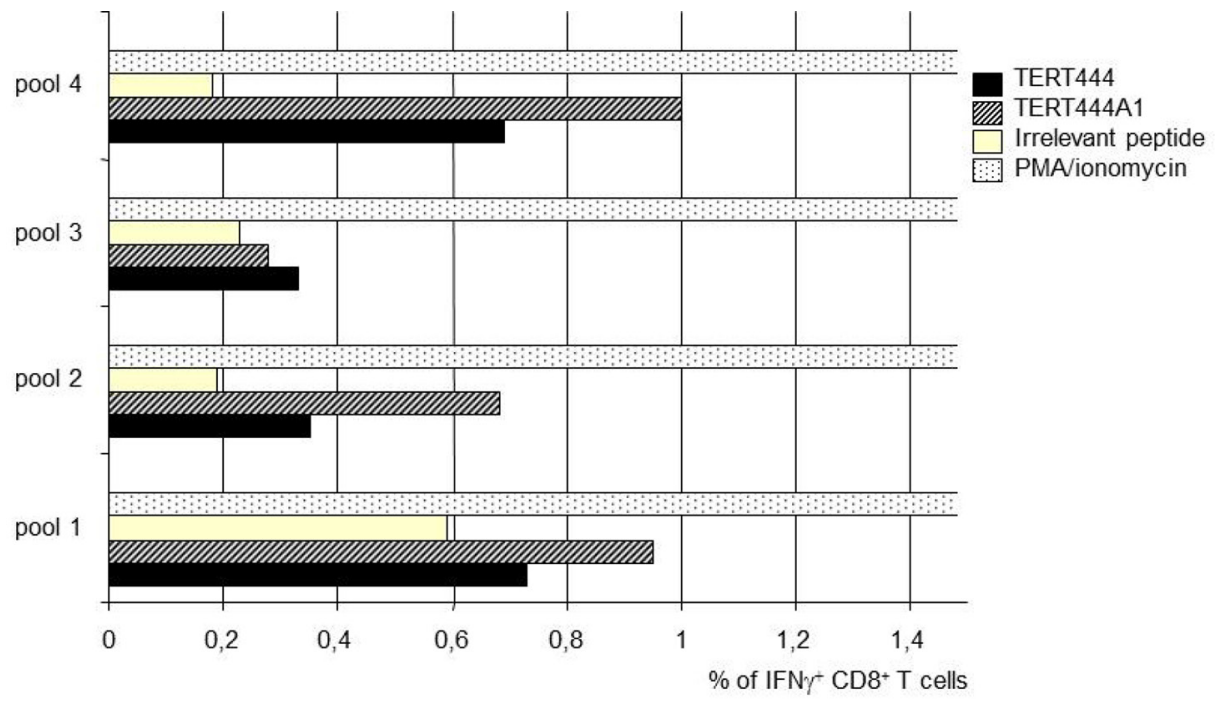

B

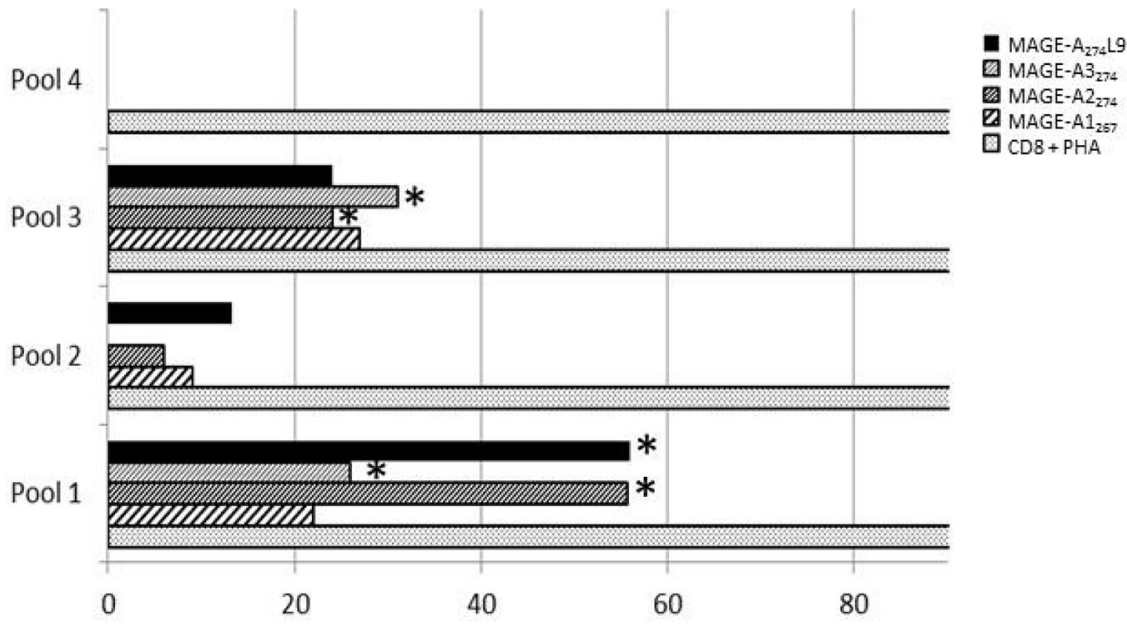

Number of spots with specific peptide - background

Figure 4: Immunogenicity of selected optimized cryptic peptides in human PBMC culture. PBMC from HLA-B*0702 healthy volunteers were stimulated 5 weeks with optimized cryptic peptides $\mathrm{TERT}_{444} \mathrm{~A} 1$ or MAGE- $\mathrm{A}_{274} \mathrm{~L} 9$ in presence of monocytederived dendritic cells. CD8 ${ }^{+}$were divided in 4 pools (numbered pool 1 to pool 4 ) and tested for the recognition of the optimized or the corresponding native peptides. (A) \% of CD8 ${ }^{+}$IFNg producing CTLs after stimulation with $\mathrm{TERT}_{444} \mathrm{~A} 1$ determined by INFg intracellular staining. PBMCs were divided in 4 pools (numbered pool 1 to pool 4) and tested for the production of intracellular IFNg in presence of TERT $_{444} \mathrm{~A}_{1}$ or $\mathrm{TERT}_{444}$ native peptide. This experiment was reproduced twice with PBMCs from two different donors giving similar results. (B) ELISpot assay of $\mathrm{CD}^{+} \mathrm{T}$ cells derived from human PBMC stimulated with MAGE- $\mathrm{A}_{274} \mathrm{~L}$ 9. PBMCs were divided in 4 pools (numbered pool 1 to pool 4) and tested for the recognition of MAGE- $\mathrm{A}_{274} \mathrm{~L} 9$ or for MAGE- $\mathrm{A}_{274}$ native variants. ELISpot assays were performed in sixplicate wells and a t test was done to evaluate the difference between the mean of number of spots in the negative control (cells loaded with an irrelevant peptide) and the mean of number of spots with the specific peptides. $*$ means that difference are statistically significative $(p \leq 0.05)$. This experiment was reproduced four times with PBMCs from four different donors. 
Table 4: Immunogenicity of optimized HLA-B $* 0702$ restricted peptides and cross recognition of the native peptides

\begin{tabular}{|c|c|c|c|c|}
\hline Antigen & Peptide & Sequence & $\begin{array}{c}\text { Immunogenicity against } \\
\text { optimized peptide }\end{array}$ & $\begin{array}{c}\text { Immunogenicity against } \\
\text { native peptide }\end{array}$ \\
\hline HER2/neu & HER 2/neu ${ }_{246} \mathrm{~A} 1$ & APKHSDCLA & $8 / 12$ & $5 / 12$ \\
\hline MAGE-A & MAGE-A $_{274}$ L9 & GPRALVETL & $18 / 18$ & $\begin{array}{l}\text { MAGE-A1 }_{267} 3 / 8 \\
\text { MAGE-A2 }_{274} 3 / 5 \\
\text { MAGE-A3 }_{274} 4 / 5\end{array}$ \\
\hline CEA & $\mathrm{CEA}_{188} \mathrm{~L} 9$ & SPRLQLSNL & $6 / 6$ & $6 / 6$ \\
\hline
\end{tabular}

HLA-B*0702 mice were vaccinated twice with the optimized peptides. Specific CTLs were detected by cytotoxicity or IFN $\gamma$ ELISPOTs against target cells loaded with the optimized peptide or the native peptide, results are presented as number of responding mice/number of vaccinated mice.

Table 5: Immunogenicity of optimized HLA-B*0702 restricted peptides, and cross recognition of the native peptide by CTLs induced by the optimized peptide in PBMC from human healthy donors; number of positive culture/number of total cultures

\begin{tabular}{|c|c|c|c|}
\hline Peptide & Sequence & $\begin{array}{c}\text { Immunogenicity against } \\
\text { optimized peptide }\end{array}$ & $\begin{array}{l}\text { Immunogenicity against native } \\
\text { peptide }\end{array}$ \\
\hline TERT $_{444} \mathrm{~A} 1$ & APRRLVQLL & $1 / 2$ & $2 / 2$ \\
\hline HER $2 /$ neu $_{246} \mathrm{~A} 1$ & APKHSDCLA & $2 / 4$ & $1 / 4$ \\
\hline MAGE-A $_{274}$ L9 & GPRALVETL & $2 / 4$ & $\begin{array}{ll}\text { MAGE-A1 }_{269} & 0 / 4 \\
\text { MAGE-A2 }_{274} & 2 / 4 \\
\text { MAGE-A3 }_{274} & 2 / 4 \\
\end{array}$ \\
\hline $\mathrm{CEA}_{188} \mathrm{L9}$ & SPRLQLSNL & $1 / 3$ & $2 / 3$ \\
\hline
\end{tabular}

tolerance to self tumor antigen was recently taken into account with a new class of cancer antigens: the neoantigens. Neo-antigens are mutation harbouring tumor epitopes, which are recognized by the immune system as non-self. Indeed, their specific T cell repertoire is not tolerized and is therefore available for specific stimulation.

Neo-antigens could then be very promising candidate in tumor vaccination providing that they are strongly immunogenic and showed really convincing results in preclinical models [19] and recently in humans in early stage but promising clinical studies [20-22].

However, the use of neo-antigens in cancer vaccination can be limited by two factors. First, the genetic heterogeneity of tumors; it is likely that neo-antigens are not expressed by all lesions of the same tumor. Neoantigen free lesions will not be targeted by neo-antigen specific T cells. Second, neo-antigens are patient specific and their use requires their previous identification in each patient individually. This can be done only in highly specialized research centers and is time consuming and expensive. Moreover, since neo-antigens are patient specific they will be administered to the individual patient without any previous demonstration of safety and efficacy in preclinical and clinical studies.

It seems therefore mandatory to find tumor antigens that have the two main properties of neo-antigens (escape self-tolerance and strong immunogenicity) while they are not patient specific and can therefore be used for treatment of all cancer patients. In several previous paper we showed that optimized TAAs derived cryptic peptides escape self-tolerance, are immunogenic and can be used for the treatment of all cancer patients $[8,13]$. They can therefore be considered as universal neo-antigen like peptide vaccines. Importantly, optimized cryptic peptides based vaccines can undergo a classical preclinical and clinical development to evaluate safety and efficacy before becoming a cancer treatment.

Tumor cryptic peptides although they escape selftolerance are not immunogenic because of their low HLA-I affinity. Their immunogenicity should be optimized before their use in cancer vaccination. We have previously shown that a substitution of the first amino acid, whatever is this amino acid by a tyrosine optimizes immunogenicity of almost all HLA-A*0201 restricted cryptic peptide [13]. 
Such optimized cryptic peptides have been successfully used in preclinical models and in cancer patients. The first anticancer therapeutic vaccine based on optimized cryptic peptide, Vx-001 was tested in a phase I/II clinical study in 116 cancer patients showing no toxicity and frequent specific immune response [14-16]. Vx-001 is currently in a randomized phase IIb in metastatic or recurrent NSCLC patients [17]. Vx-001 is designated to HLA-A*0201 expressing patients representing $45 \%$ of humans. Developing optimized cryptic peptide based vaccine for patients expressing other HLA molecules is then necessary to increase the proportion of patients suitable to be treated with such products.

The strategy for enhancing the immunogenicity of cryptic peptides, that because of their low MHC I affinity are non-immunogenic, consists in increasing their affinity for the MHC I molecules through amino acids substitutions [13] while preserving the antigenicity of such optimized peptides. CTL generated by optimized peptides should indeed cross-react with the corresponding native peptides, which are presented at the tumor cell surface. Peptide affinity for MHC I molecules mainly depends on the presence at well-defined positions of residues called "primary anchor residues", which are MHC I allele specific. Other residues at positions called "secondary anchor positions" that are less HLA specific may play a role in the HLA/peptide interaction. The rules to select and optimized cryptic peptides is then totally different for each HLA molecule. In this study, we have defined how to design optimized cryptic peptides for HLA-B*0702, allele that is expressed by $25 \%$ of human population.

High affinity HLA-B*0702/peptide interaction requires the presence of a proline and a leucine at primary anchor positions 2 and c-terminal respectively as well as an alanine and a lysine/arginine at secondary positions 1 and 3 respectively. Our initial strategy was to select HLA-B*0702 restricted cryptic peptides having at least one primary anchor motif (Proline at position 2 and if possible leucine at position 9) and unfavourable residues at position 1 and position 3. Thus substituting unfavourable residues at the two secondary positions with favourable ones should enhance HLA-B*0702 affinity and immunogenicity of selected cryptic peptides. As expected all selected peptides exhibited a low affinity which is the main feature of a cryptic peptide. However, substitutions of residues at position 3 although they enhanced affinity of all tested peptides led to the loss of the cross-recognition of the native cryptic peptide. This is probably due to the fact that position 3 is close to the peptide segment that interacts with the T Cell Receptor (position 4 to position 8) and substitution at position 3 alters the conformation of this TCR contacting peptide segment. Since the absence of a favourable residue at position 3 (lysine or arginine) seems to be deleterious for the HLA-B*0702/ peptide interaction (compare affinity of $\mathrm{Hsp} 70_{115} \mathrm{~A} 1$ Hsp70 ${ }_{115} \mathrm{~A} 1 \mathrm{R} 3$ and MAGE-A $1_{121} \mathrm{~A} 1$ - MAGE-A $1_{121} \mathrm{~A} 1 \mathrm{R} 3$ ) we decided to select cryptic peptide candidates based on the presence of a proline at position 2, a Lysine/Arginine at position 3 and an unfavorable residue at position 1. Almost all peptides having this profile were non-immunogenic (TERT $_{444}$, HER-2/neu ${ }_{246}$, MAGE-A1 ${ }_{267}$, MAGE-A2 274 , $\mathrm{CEA}_{188}$ ) or were very weakly immunogenic (HER-2/ neu $_{1151}$ and MAGE-A $3_{274}$ ). Importantly immunogenicity was restored when an alanine has substituted the residue at position 1 demonstrating the importance of this position in the HLA-B*0702/peptide interaction. CTLs induced by all these optimised peptides recognized their native counterpart. This is easily explained by the fact that position 1 is separated from the TCR contacting segment of the peptide by two anchor positions 2 and 3 that protect this segment from any modification brought at position 1 .

Immunotherapy is now considered as a really promising approach to treat cancer. Recently, the discovery and development in this domain was largely focused on immune checkpoint inhibitors such as antiCTLA-4 or anti PD-1/PD-L1 [23].

PD-1 is expressed on activated T cells. It is known to play a major role in tumor escape since after binding to its ligands PD-L1 or PD-L2, PD-1 down regulates signalling by the TCR leading to immune suppression by $\mathrm{T}$ cell anergy or apoptosis [24].

Inhibition of the PD-1/PD-L1 pathway leads to the suppression the tumor microenvironment negative effect on the immune response. However, PD-1 inhibitors are very weakly or not at all efficient in the absence of tumor infiltrating $\mathrm{T}$ cells that are frequent in tumors with high mutational load.

In this context inducing a strong immune response with optimized cryptic peptides that targets antigens expressed by all tumor cells, could potentiate the action of immune checkpoint inhibitors by inducing tumor specific T cells that could infiltrate the tumor. Moreover, optimized cryptic peptide induced immune response will render sensitive to PD-1 inhibitors treatment tumors that are naturally non immunogenic because they have low mutational load and are not therefore infiltrated by $\mathrm{T}$ Infiltrating Lymphocytes (TILs). Thus, combining optimized cryptic peptide based vaccine and immune checkpoint inhibitors could then increase dramatically the proportion of patients that could benefit from these treatments.

In this study, we describe how to optimize immunogenicity of HLA-B*0702 restricted cryptic peptides from TAAs.

These results open the way for the development of universal neo-antigen like therapeutic vaccine designated to HLA-B*0702 patients, representing at least $25 \%$ of the human population, which have the two main properties of neo-antigens -they escape self-tolerance and are immunogenic- while unlike neo-antigens they are not patient specific and can be used for vaccination of all cancer patients. 


\section{MATERIALS AND METHODS}

\section{Transgenic mice}

The HLA-B7 H-2 class-I knockout mice were previously described [25].

\section{Cells}

HLA-B*0702 transfected murine RMA-B7 and human T2-B7 cells were previously described [25].

\section{Peptides and plasmids} France).

Peptides were synthesized by Millegen (Labège,

\section{Measurement of peptide relative affinity to HLA-B $* 0702$}

The protocol used has been described previously [25]. Briefly, T2-B7 cells were incubated at $37^{\circ} \mathrm{C}$ for 16 hours with peptides concentrations ranging from $100 \mu \mathrm{M}$ to $0.1 \mu \mathrm{M}(100 \mu \mathrm{M}, 10 \mu \mathrm{M}, 1 \mu \mathrm{M}$ and $0.1 \mu \mathrm{M})$, and then stained with ME-1 monoclonal antibody $(\mathrm{mAb})$ to quantify the surface expression of HLA-B*0702. For each peptide concentration, the HLA-B*0702 specific staining was calculated as the percentage of staining obtained with $100 \mu \mathrm{M}$ of the reference peptide $\mathrm{CMV}_{265-274}$ (R10V; RPHERNGFTV, SEQ ID NO: 9). The relative affinity (RA) was determined as: $\mathrm{RA}=($ Concentration of each peptide that induces $20 \%$ of HLA-B*0702expression/Concentration of the reference R10V peptide that induces $20 \%$ of HLA-B*0702 expression). In case of non-binders peptide, RA is not evaluable since the $20 \%$ of HLA-B*0702 expression is not reach even with the highest concentration of peptide.

\section{Vaccination of HLA-B*0702 transgenic mice}

Mice were injected subcutaneously with $100 \mu \mathrm{g}$ of peptide emulsified in Incomplete Freund's Adjuvant (IFA) in the presence of $150 \mu \mathrm{g}$ of the I-A $\mathrm{A}^{\mathrm{b}}$ restricted HBVcore ${ }_{128}$ T helper epitope (TPPAYRPPNAPIL) twice at two weeks interval.

A particular protocol was applied for MAGE-A ${ }_{274} \mathrm{~L} 9$, with two injections of this peptide at two weeks interval and 15 days later one injection with each one of the native peptide.

\section{Cytotoxic assay}

Eleven days after the last vaccination $5 \times 10^{7}$ spleen cells were in vitro stimulated with the corresponding native peptide $(10 \mu \mathrm{M})$ in RPMI 1640 medium supplemented with $10 \%$ FCS, $2 \mu \mathrm{M}$ glutamine and antibiotics. On day 6 of culture the bulk responder populations were tested for specific cytotoxicity. Target cells were labelled with $100 \mu \mathrm{Ci}$ of ${ }^{51} \mathrm{Cr}$ for $60 \mathrm{~min}$, plated in 96-well V-bottomed plates $\left(3 \times 10^{3}\right.$ cell/well in $100 \mu \mathrm{L}$ of RPMI 1640 medium) and, when necessary, pulsed with peptides of interest or an irrelevant peptide $(1 \mu \mathrm{M}$, irrelevant peptide is not restricted by HLA-B*0702) at $37^{\circ} \mathrm{C}$ for 2 hours. Effectors were then added in the wells and incubated at $37^{\circ} \mathrm{C}$ for 4 hours at a ratio of 30 effector cells for 1 target cell. Percentage of specific lysis was determined as: $\%$ Lysis $=$ (Experimental Release-Spontaneous Release) / (Maximal Release-Spontaneous Release) $\times 100$. Spontaneous release is obtained using medium only, maximum release with $\mathrm{HCl} 0.1 \mathrm{M}$.

\section{Murine IFN $\gamma$ ELISPOT assay}

Seven days after the last vaccination, spleens were removed and T cells were isolated by Ficoll centrifugation and tested ex vivo for the recognition of $10 \mu \mathrm{M}$ of either the native or optimized peptide. IFN $\gamma$ producing T cells were quantified by ELISpot using the Diaclone Kit Murine IFN $\gamma$ ELISpot (Besançon, France) according to manufacturer's recommendations. 250000 spleen T cells were distributed per well and tested for the recognition of $10 \mu \mathrm{M}$ of either the native or optimized peptide. Positive control was Concanavalin A and negative control was medium alone. All conditions were tested in sixplicates.

\section{Generation of CTL from human PBMC}

PBMC were collected by leukapheresis from healthy HLA-A*B702 volunteers. Dendritic cells (DC) were produced from adherent cells cultured with $500 \mathrm{IU} / \mathrm{ml}$ GM-CSF and $500 \mathrm{IU} / \mathrm{ml} \mathrm{IL-4,} \mathrm{in} \mathrm{complete} \mathrm{synthetic}$ medium (AIMV) for seven days. On day 7, DCs were pulsed with $10 \mu \mathrm{M}$ of peptide during 2 hours and $\mathrm{CD} 8^{+}$ cells were purified by negative selection with CD8 Dynabeads Untouched Human CD8. CD8 ${ }^{+}$cells $\left(2 \times 10^{5}\right)$ $+\mathrm{CD}^{-}$cells $\left(6 \times 10^{4}\right)$ were stimulated with $3 \times 10^{4}$ peptide-pulsed DC in AIMV medium supplemented with $1000 \mathrm{IU} / \mathrm{ml} \mathrm{IL}-6$ and $5 \mathrm{IU} / \mathrm{ml} \mathrm{IL}-12$ in round-bottomed 96-well plates.

From day 7, cultures were stimulated weekly with peptide-loaded DC in the presence of $20 \mathrm{IU} / \mathrm{ml} \mathrm{IL}-2$ and $10 \mathrm{ng} / \mathrm{ml} \mathrm{IL-7,} 1 \mu \mathrm{g} / \mathrm{ml}$ anti-CD40 and $500 \mathrm{IU} / \mathrm{ml} \mathrm{IFN} \gamma$.

After the third stimulation, CD8 cells were maintained in AIMV supplemented with $20 \mathrm{IU} / \mathrm{ml}$ IL-2 during 7 days. Cultures were starved overnight with AIMV and then were tested in an intracellular IFN $\gamma$ and an IFN $\gamma$ ELISpot assay.

\section{IFN $\gamma$ intracellular staining}

Stimulated $\mathrm{T}$ cells $\left(10^{5}\right)$ from each pool were incubated with $2 \times 10^{5} \mathrm{~T} 2$ cells loaded with stimulating peptide in the presence of $20 \mu \mathrm{g} / \mathrm{ml}$ Brefeldin-A (Sigma, Oakville, Canada). Six hours later they were washed, 
stained with r-phycoerythrin-conjugated anti-CD8 antibody (Caltag Laboratories, Burlingame, CA, USA) in PBS for $25 \mathrm{~min}$ at $4^{\circ} \mathrm{C}$, washed again, and fixed with $4 \%$ PFA. The cells were then permeabilized with PBS, $0.5 \%$ BSA, $0.2 \%$ saponin (Sigma, Oakville, Canada), and labelled with an allophycocyanin-conjugated anti-IFN $\gamma$ $\mathrm{mAb}$ (PharMingen, Mississauga, Canada) for $25 \mathrm{~min}$ at $4^{\circ} \mathrm{C}$ before analysis with a FACSCalibur ${ }^{\circledR}$ flow cytometer.

\section{Human IFN $\gamma$ ELISPOT assay}

Stimulated T cells were splited in four pools and IFN $\gamma$ producing $\mathrm{T}$ cells was quantified in each pool by ELISpot using the Diaclone Kit Human IFN $\gamma$ ELISpot (Besançon, France) according to manufacturer's recommendations. 250000 cells were distributed per well and tested for the recognition of $10 \mu \mathrm{M}$ of either the native or optimized peptide. Positive control was Concanavalin A and negative control was medium alone or an irrelevant peptide. All conditions were tested in sixplicates.

\section{CONFLICTS OF INTEREST}

The authors have no conflicts of interests.

\section{REFERENCES}

1. Naftzger C, Takechi Y, Kohda H, Hara I, Vijayasaradhi S, Houghton AN. Immune response to a differentiation antigen induced by altered antigen: a study of tumor rejection and autoimmunity. Proc Natl Acad Sci U S A. 1996; 93:14809-14814.

2. Vierboom MP, Nijman HW, Offringa R, van der Voort EI, van Hall T, van den Broek L, Fleuren GJ, Kenemans P, Kast WM, Melief CJ. Tumor eradication by wild-type p53-specific cytotoxic T lymphocytes. J Exp Med. 1997; 186:695-704.

3. Weber LW, Bowne WB, Wolchok JD, Srinivasan R, Qin J, Moroi Y, Clynes R, Song P, Lewis JJ, Houghton AN. Tumor immunity and autoimmunity induced by immunization with homologous DNA. J Clin Invest. 1998; 102:1258-1264.

4. Overwijk WW, Tsung A, Irvine KR, Parkhurst MR, Goletz TJ, Tsung K, Carroll MW, Liu C, Moss B, Rosenberg SA, Restifo NP. gp100/pmel 17 is a murine tumor rejection antigen: induction of "self"-reactive, tumoricidal $\mathrm{T}$ cells using high-affinity, altered peptide ligand. J Exp Med. 1998; 188:277-286.

5. Bowne WB, Srinivasan R, Wolchok JD, Hawkins WG, Blachere NE, Dyall R, Lewis JJ, Houghton AN. Coupling and uncoupling of tumor immunity and autoimmunity. J Exp Med. 1999; 190:1717-1722.

6. Colella TA, Bullock TN, Russell LB, Mullins DW, Overwijk WW, Luckey CJ, Pierce RA, Restifo NP, Engelhard VH. Self-tolerance to the murine homologue of a tyrosinase-derived melanoma antigen: implications for tumor immunotherapy. J Exp Med. 2000; 191:1221-1232.
7. Hawkins WG, Gold JS, Dyall R, Wolchok JD, Hoos A, Bowne WB, Srinivasan R, Houghton AN, Lewis JJ. Immunization with DNA coding for gp100 results in CD4 T-cell independent antitumor immunity. Surgery. 2000; 128:273-280.

8. Gross DA, Graff-Dubois S, Opolon P, Cornet S, Alves P, Bennaceur-Griscelli A, Faure O, Guillaume P, Firat H, Chouaib S, Lemonnier FA, Davoust J, Miconnet I, et al. High vaccination efficiency of low-affinity epitopes in antitumor immunotherapy. J Clin Invest. 2004; 113:425-433.

9. Ruiz R, Hunis B, Raez LE. Immunotherapeutic agents in non-small-cell lung cancer finally coming to the front lines. Curr Oncol Rep. 2014; 16:400.

10. Tyagi P, Mirakhur B. MAGRIT: the largest-ever phase III lung cancer trial aims to establish a novel tumor-specific approach to therapy. Clin Lung Cancer. 2009; 10:371-374.

11. Pol J, Bloy N, Buque A, Eggermont A, Cremer I, SautesFridman C, Galon J, Tartour E, Zitvogel L, Kroemer G, Galluzzi L. Trial Watch: Peptide-based anticancer vaccines. Oncoimmunology. 2015; 4:e974411.

12. Martin SD, Coukos G, Holt RA, Nelson BH. Targeting the undruggable: immunotherapy meets personalized oncology in the genomic era. Ann Oncol. 2015.

13. Tourdot S, Scardino A, Saloustrou E, Gross DA, Pascolo S, Cordopatis P, Lemonnier FA, Kosmatopoulos K. A general strategy to enhance immunogenicity of lowaffinity HLA-A2. 1-associated peptides: implication in the identification of cryptic tumor epitopes. Eur J Immunol. 2000; 30:3411-3421.

14. Vetsika EK, Konsolakis G, Aggouraki D, Kotsakis A, Papadimitraki E, Christou S, Menez-Jamet J, Kosmatopoulos K, Georgoulias V, Mavroudis D. Immunological responses in cancer patients after vaccination with the therapeutic telomerase-specific vaccine Vx-001. Cancer Immunol Immunother. 2012; 61:157-168.

15. Kotsakis A, Vetsika EK, Christou S, Hatzidaki D, Vardakis N, Aggouraki D, Konsolakis G, Georgoulias V, Christophyllakis C, Cordopatis P, Kosmatopoulos K, Mavroudis D. Clinical outcome of patients with various advanced cancer types vaccinated with an optimized cryptic human telomerase reverse transcriptase (TERT) peptide: results of an expanded phase II study. Ann Oncol. 2012; 23:442-449.

16. Mavroudis D, Bolonakis I, Cornet S, Myllaki G, Kanellou P, Kotsakis A, Galanis A, Nikoloudi I, Spyropoulou M, Menez J, Miconnet I, Niniraki M, Cordopatis P, et al. A phase I study of the optimized cryptic peptide TERT(572y) in patients with advanced malignancies. Oncology. 2006; 70:306-314.

17. Georgoulias V, Douillard JY, Khayat D, Manegold C, Rosell R, Rossi A, Menez-Jamet J, Iche M, Kosmatopoulos K, Gridelli C. A multicenter randomized phase IIb efficacy study of Vx-001, a peptide-based cancer vaccine as maintenance treatment in advanced non-small- 
cell lung cancer: treatment rationale and protocol dynamics. Clin Lung Cancer. 2013; 14:461-465.

18. Sidney J, Southwood S, del Guercio MF, Grey HM, Chesnut RW, Kubo RT, Sette A. Specificity and degeneracy in peptide binding to HLA-B7-like class I molecules. J Immunol. 1996; 157:3480-3490.

19. Gubin MM, Artyomov MN, Mardis ER, Schreiber RD. Tumor neoantigens: building a framework for personalized cancer immunotherapy. J Clin Invest. 2015; 125:3413-3421.

20. Tran E, Turcotte S, Gros A, Robbins PF, Lu YC, Dudley ME, Wunderlich JR, Somerville RP, Hogan K, Hinrichs CS, Parkhurst MR, Yang JC, Rosenberg SA. Cancer immunotherapy based on mutation-specific CD4+ $\mathrm{T}$ cells in a patient with epithelial cancer. Science. 2014; 344:641-645.

21. Robbins PF, Lu YC, El-Gamil M, Li YF, Gross C, Gartner J, Lin JC, Teer JK, Cliften P, Tycksen E, Samuels Y, Rosenberg SA. Mining exomic sequencing data to identify mutated antigens recognized by adoptively transferred tumor-reactive T cells. Nat Med. 2013; 19:747-752.

22. Carreno BM, Magrini V, Becker-Hapak M, Kaabinejadian S, Hundal J, Petti AA, Ly A, Lie WR, Hildebrand WH, Mardis ER, Linette GP. Cancer immunotherapy. A dendritic cell vaccine increases the breadth and diversity of melanoma neoantigen-specific T cells. Science. 2015; 348:803-808.

23. Wolchok JD. PD-1 Blockers. Cell. 2015; 162:937.

24. Blank C, Brown I, Peterson AC, Spiotto M, Iwai Y, Honjo T, Gajewski TF. PD-L1/B7H-1 inhibits the effector phase of tumor rejection by $\mathrm{T}$ cell receptor (TCR) transgenic CD8+ T cells. Cancer Res. 2004; 64:1140-1145.

25. Rohrlich PS, Cardinaud S, Firat H, Lamari M, Briand P, Escriou N, Lemonnier FA. HLA-B*0702 transgenic, $\mathrm{H}-2 \mathrm{KbDb}$ double-knockout mice: phenotypical and functional characterization in response to influenza virus. Int Immunol. 2003; 15:765-772. 